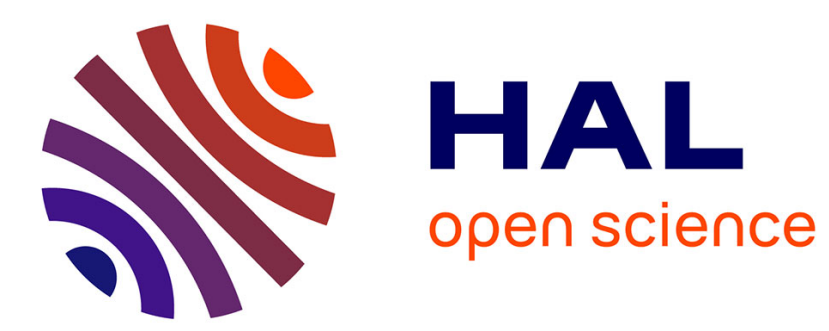

\title{
NEUTRON SCATTERING AND PHYSISORPTION
}

\author{
I. Marlow, R. Thomas, T. Trewern, J. White
}

\section{To cite this version:}

I. Marlow, R. Thomas, T. Trewern, J. White. NEUTRON SCATTERING AND PHYSISORPTION. Journal de Physique Colloques, 1977, 38 (C4), pp.C4-19-C4-25. 10.1051/jphyscol:1977403 . jpa00217119

\section{HAL Id: jpa-00217119 \\ https://hal.science/jpa-00217119}

Submitted on 1 Jan 1977

HAL is a multi-disciplinary open access archive for the deposit and dissemination of scientific research documents, whether they are published or not. The documents may come from teaching and research institutions in France or abroad, or from public or private research centers.
L'archive ouverte pluridisciplinaire HAL, est destinée au dépôt et à la diffusion de documents scientifiques de niveau recherche, publiés ou non, émanant des établissements d'enseignement et de recherche français ou étrangers, des laboratoires publics ou privés. 


\title{
NEUTRON SCATTERING AND PHYSISORPTION
}

\author{
I. MARLOW, R. K. THOMAS (*), T. D. TREWERN \\ Physical Chemistry Laboratory, South Parks \\ Road, Oxford 0X1 3Z2, U.K.
}

and

\section{J. W. WHITE}

Institut Laue-Langevin, 38042 Grenoble Cedex, France

\begin{abstract}
Résumé. - On décrit des expériences de diffraction de neutrons par du méthane ou de l'ammoniac adsorbés sur un noir de carbone graphitisé (Graphon). La diffraction par le méthane deutéré adsorbé montre que, pour un recouvrement de 0,7 , il forme une couche épitaxique de structure $\sqrt{3} \times \sqrt{3}$. Entre 50 et $60 \mathrm{~K}$ il subit un changement de phase de l'état solide bidimensionnel à l'état liquide (point de fusion du méthane $=89,7 \mathrm{~K}$ ). Des résultats semblables sont obtenus avec le méthane deutéré fixé sur un échantillon de graphon contenant du potassium intercalé. L'effet de l'adsorption de méthane sur les intensités des raies 001 des deux substrats permet d'estimer que le méthane est à une distance de $3,3 \pm 0,2 \AA$ de la surface.

L'ammoniac- $d_{3}$ sur graphon a un comportement très différent. $L$ 'isotherme est de type III et, à basses températures, il se forme par désorption de l'ammoniac solide tridimensionnel. Celui-ci possède des propriétés de fusion anormales dont on montre qu'elles sont en rapport avec les isobares d'adsorption du système. L'interprétation détaillée des résultats met en évidence le lien étroit qui existe entre adsorption et nucléation hétérogène.

Les expériences de diffusion quasi élastique sur le système ammoniac-graphon montrent que l'ammoniac adsorbé présente une diffusion translationnelle beaucoup plus rapide à la surface que dans la masse. Ceci est attribué à la rupture du réseau de liaisons hydrogènes normalement présent dans le liquide.
\end{abstract}

\begin{abstract}
Neutron scattering experiments on methane and ammonia adsorbed on a graphitized carbon black are described.

Diffraction from adsorbed deuterated methane shows that, at a coverage of 0.7 , it forms an epitaxial layer with a $\sqrt{3} \times \sqrt{3}$ structure. Between 50 and $60 \mathrm{~K}$ it undergoes a phase transition from two-dimensional solid to liquid (bulk melting point $=89.7 \mathrm{~K}$ ). Similar results are obtained for deuterated methane on a sample of graphon intercalated with potassium. From the effect of adsorbed methane on the intensities of 001 peaks of both substrates the carbon atom of the methane is estimated to be $3.3 \pm 0.2 \AA$ from the surface.

Ammonia- $d_{3}$ on graphon behaves quite differently from methane. It follows a type III isotherm and at low temperatures desorbs from the surface to form bulk ammonia. This has anomalous melting properties which are shown to be related to adsorption isobars for the system. The detailed interpretation of the results emphasizes the close link between adsorption and heterogeneous nucleation.

Quasielastic experiments on the ammonia-graphon system show that the adsorbed ammonia is undergoing translational diffusion on the surface which is much faster than in the bulk. This is attributed to the breaking up of the hydrogen bonded network normally present in the liquid.
\end{abstract}

Neutron scattering is an ideal technique for studying physical adsorption at a molecular level. The wavelength of thermal neutrons is suitable for probing the structure of an adsorbate, and analysis of small exchanges of energy between neutrons and adsorbate makes it possible to observe either the motion of individual adsorbed molecules or coherent

(*) All communications to be addressed to RKT. motion of the whole adsorbate. At present, the available energy of neutron beams and the resolution of neutron spectrometers cover the time scale $10^{-8}-10^{-14} \mathrm{~s}$, extending from relatively slow diffusion $\left(D \sim 10^{-8} \mathrm{~cm}^{2} \mathrm{~s}^{-1}\right)$ to quite high vibration frequencies $\left(\sim 2000 \mathrm{~cm}^{-1}\right)$.

In addition to the appropriate wavelength and energy of thermal neutrons for surface experiments there are several advantages of the technique, 
particularly for diffraction from adsorbates, resulting from the weak scattering of neutrons from atomic nuclei. Firstly, any vapour present has a negligible effect on the neutron beam. The structure and dynamics of an adsorbate are therefore easily studied over ranges of temperature where adsorption isotherms are also easily measured. Secondly, and most important for structural work, it is possible to use powdered samples, again opening up a range of experiments on systems whose thermodynamic properties are readily accessible. Finally, many common adsorbents scatter neutrons weakly while most adsorbate molecules of chemical interest contain protons whose incoherent scattering cross section is an order of magnitude greater than that of any other nucleus. Proton containing molecules are ideal for quasielastic scattering experiments for studying the diffusive motions of adsorbed species. On substitution of deuterium for hydrogen the same molecules will have coherent cross sections comparable with those of the adsorbent. They are therefore capable of giving relatively strong adsorbate diffraction patterns. These properties are illustrated in table I which gives coherent and incoherent scattering cross sections per gram for a selection of likely adsorbents and adsorbates. Coherent cross sections only give an approximate idea of the total intensity to be expected in a diffraction pattern. In practice, diffraction from adsorbate and adsorbent will occur at different Bragg angles so that the ratios given in column 3 of table I may be even more favourable for observation of adsorbate structure.

\section{TABLE I}

\section{Scattering cross sections of some substrates and adsorbents of interest in physisorption}

Adsorbent cross sections are calculated for a surface area of $100 \mathrm{~m}^{2} \mathrm{gm}^{-1}$ and a molecular area of $16.2 \AA^{2}$.

$\begin{array}{lcc}\text { Substance } & \begin{array}{c}\text { Coherent } \\ \text { Cross Section } \\ \left(\times 10^{5} \mathrm{~m}^{2} \mathrm{gm}^{-1}\right)\end{array} & \begin{array}{c}\text { Incoherent } \\ \text { Cross Section } \\ \left(\times 10^{5} \mathrm{~m}^{2} \mathrm{gm}^{-1}\right)\end{array} \\ \text { Graphon } & - & - \\ \text { Silica } & 2.8 & 0 \\ \text { Alumina } & 1.1 & 0 \\ \text { Titania } & 0.9 & 0 \\ \text { Ammonia } & 0.7 & 0.2 \\ \text { Methane } & 0.16\left(\mathrm{ND}_{3}\right) & 1.5\left(\mathrm{NH}_{3}\right) \\ & 0.16\left(\mathrm{CD}_{4}\right) & 2.0\left(\mathrm{CH}_{4}\right)\end{array}$

Several papers have already been published on neutron scattering from physisorption systems. The diffraction work has all been done on the partially oriented adsorbent, exfoliated graphite, using as adsorbates, nitrogen [1,2] and the inert gases [3]. Quasielastic experiments have been made on methane on activated charcoal $[4,5]$ and on a recompressed sample of exfoliated graphite [6].

All of the systems above obey type II isotherms. The present paper describes a set of diffraction experiments on another type II system, methane on graphitized carbon black (graphon), and both diffraction and quasielastic scattering experiments on the ammonia-graphon system which follows a type III isotherm. Graphon was chosen for these experiments because it has been well studied by a variety of techniques [7], has a large surface area and a homogeneous distribution of adsorption sites.

1. Experimental details. - Two forms of graphon were used. The ammonia experiments were made on a graphitized carbon black with surface area $86 \mathrm{~m}^{2} \mathrm{gm}^{-1}$ which has been described by Ash and Findenegg [8] and was provided by D. H. Everett. The methane experiments were done on a sample of Vulcan III obtained from the National Physical Laboratory, Teddington, U.K. This has been agreed as a standard adsorbent for surface area measurement [9] and has an area of $71 \mathrm{~m}^{2} \mathrm{gm}^{-1}$. Graphon was intercalated with potassium by equilibration through the vapour phase [10]. Deuterated chemicals were obtained from Merck, Sharp and Dohme.

The samples were contained in welded aluminium cans or silica tubes and outgassed at $350^{\circ} \mathrm{C}$ and $10^{-6} \mathrm{mmHg}$ for 24 hours. Known volumes of adsorbent gas were deposited slowly on to the substrate at temperatures where the vapour pressure was appreciable before further cooling. Coverages quoted in this paper refer to the number of adsorbate molecules per site available for nitrogen adsorption taking the area of nitrogen to be $16.2 \AA$. The temperature stability of the cryostats used was better than $1^{\circ}$ and the absolute accuracy better than $5^{\circ}$. The diffractometers used were CURRAN $(\lambda=2.63 \AA)$ and MKVI $(\lambda=1.09 \AA)$ diffractometers at the AERE, Harwell and DIA $(\lambda=2.98 \AA)$ and $\operatorname{DIB}(\lambda=2.4 \AA)$ at the Institut Laue-Langevin, Grenoble. Quasielastic experiments were done on the multichopper time of flight spectrometer, IN5, at the I.L.L. Standard programs available at the I.L.L. were used for the reduction of the raw time of flight data.

2. Results and discussion. - 2.1 METHANE ON GRAPHON AND POTASSIUM INTERCALATED GRAPHON. - The adsorption of methane on graphon and the closely related adsorbent, exfoliated graphite, follow type II isotherms $[11,12]$ indicating that the adsorbate tends to form a fairly well defined monolayer. It is therefore expected to form a twodimensional solid at sufficiently low temperatures. Indeed, Thomy and Duval [12] have observed breaks in the isotherms for methane on exfoliated graphite which they attribute to a phase transition between two dimensional solid and liquid. In their experiments the lowest transition temperature they measured was $77.3 \mathrm{~K}$ for 0.9 layers of methane. The transition was found to be extremely sharp with 
exfoliated graphite as adsorbent but other work of Thomy and Duval [13] indicates that such transitions will occur over a wider temperature range on graphitized carbon blacks.

The results of neutron diffraction from deuterated methane adsorbed on the graphon, Vulcan III, at a coverage of 0.7 and over a range of temperatures from 10 to $70 \mathrm{~K}$ are shown in figure 1 . The patterns were obtained by direct subtraction of the substrate pattern from the pattern obtained after adsorption of methane. The sample had not been moved in any way and was sufficiently small that there should be no errors in the subtraction arising from self shielding or small angle scattering effects. There is one source of error which shows in the difference pattern at $70 \mathrm{~K}$ because all the patterns in figure 1 were obtained by subtraction of the $30 \mathrm{~K}$ substrate pattern. Because of thermal expansion of the graphite there is a dip in the difference pattern at $2 \theta=42^{\circ}$. This is also the cause of the artificially sharp separation of the two peaks in the pattern at $10 \mathrm{~K}$ where a dip owing to poor subtraction occurs at about $2 \theta=39^{\circ}$.

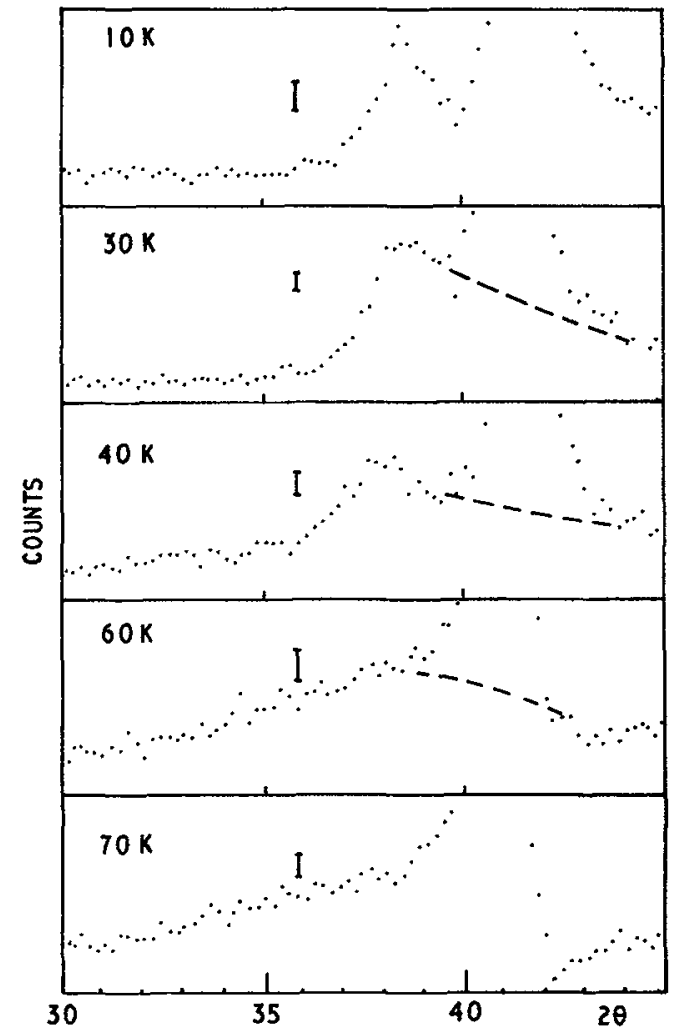

FIG. 1. - Diffraction Patterns from $\mathrm{CD}_{4}$ Adsorbed on Graphon. Coverage $=0.7$. Background has been subtracted. Error bars are given separately on each pattern.

The low temperature patterns contain two peaks. The intense one at $2 \theta=41.5^{\circ}(\lambda=2.4 \AA)$ comes from the 002 reflection of graphite whose intensity is increased by about $3 \%$ on adsorption of methane. The second peak at $2 \theta=38^{\circ}$ is a reflection from the methane layer. It has the characteristic shape expected for diffraction from a two-dimensional layer in a powdered sample [14] the peak extending beyond the enhanced 002 reflection of the substrate. The ratio of $\sin \theta$ for this peak to that of the second graphite reflection which also has the shape expected for diffraction from a two dimensional layer, is $\sqrt{3}$ showing that the methane is in registry with the basal planes of graphite which make up most of the graphon surface. The adsorbed methane at low temperatures is in an epitaxial phase of $\sqrt{3} \times \sqrt{3}$ structure as has already been found for nitrogen [1,2] and krypton [3] on exfoliated graphite.

At temperatures of 60 and $70 \mathrm{~K}$ the 2-D peak is replaced by a broader, more symmetrical peak with a maximum at lower values of $2 \theta$. The exact position of the maximum is difficult to fix because of the overlap by the enhanced 002 reflection of the substrate. The broad peak is assumed to be associated with a liquid phase on the surface. Because the coverage is less than a monolayer such a phase transition will increase the area available per molecule and therefore shift the diffraction peak to lower values of $2 \theta$. The difference pattern at $50 \mathrm{~K}$ is clearly a mixture of $2-\mathrm{D}$ solid and liquid peaks indicating that the phase transition is not as sharp on graphon as on exfoliated graphite.

The difficulty of doing experiments on graphon is that the most pronounced features of the adsorbate pattern are close to the broad and intense 002 reflection from the graphite. This makes it necessary to count for a long time. Others have overcome this problem by using various forms of exfoliated graphite partially oriented with respect to the neutron beam $[1,2,3]$. This loses the advantage of the much higher surface area of graphon and the consequent advantages of working with reasonably small samples. We have partly overcome the problem by intercalating graphon with potassium. Two compounds are readily formed, $\mathrm{C}_{8} \mathrm{~K}$, a stage I compound where the $c$-axis spacing of the graphite has effective been increased from $3.35 \AA$ to $5.4 \AA$ and $C_{24} K$, a stage $I I$ compound with an effective layer spacing of $4.4 \AA$ [10]. Unfortunately, they are difficult to handle, being pyrophoric.

That intercalation is a useful way of modifying an adsorbent is illustrated by the diffraction patterns of deuterated methane on a sample of intercalated Vulcan III. These are shown for a coverage of 0.7 and various temperatures, in figure 2 . The substrate was actually a mixture of the two compounds and the positions of their diffraction peaks are marked. There is a strong diffraction peak from a 2-D layer of methane which is almost free from interference by substrate reflections. The peak is in exactly the same position as for graphon as substrate, again demonstrating that methane forms an epitaxial layer on the surface. The whole shape of the peak is now 


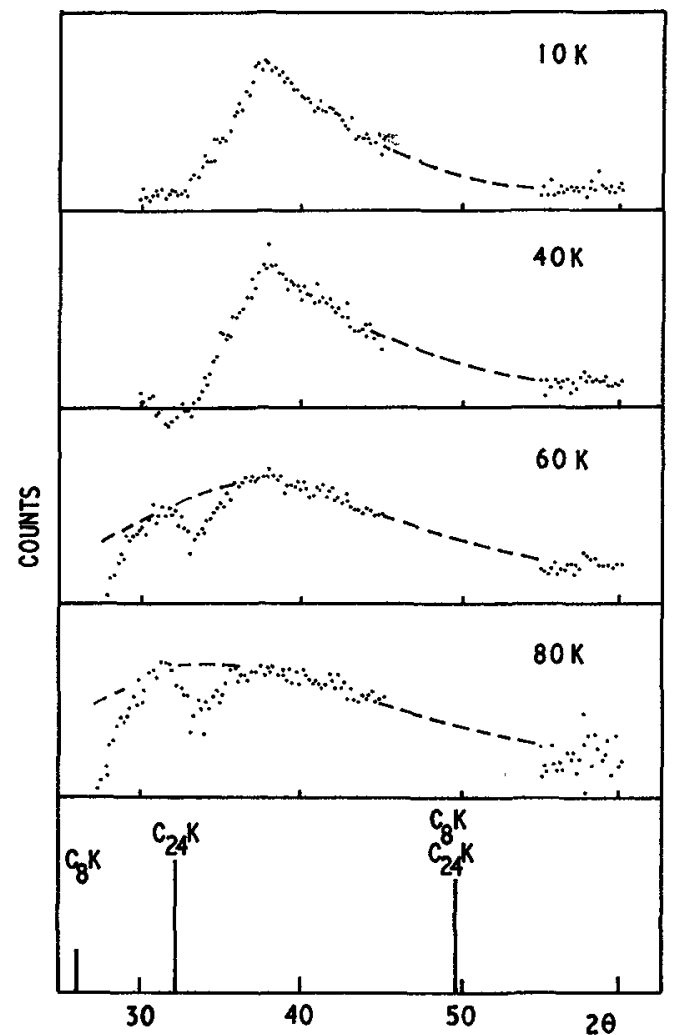

FIG. 2. - Diffraction Patterns from $\mathrm{CD}_{4}$ Adsorbed on Potassium Intercalated Graphon. Coverage $=0.7$. Background has been subtracted. $\mathrm{C}_{24} \mathrm{~K}$ and $\mathrm{C}_{8} \mathrm{~K}$ peaks are marked in the lowest diagram.

sufficiently clear that the size of the methane rafts can be estimated to be $35 \AA$ in diameter. As on graphon there is a phase change between 40 and $60 \mathrm{~K}$ when the peak becomes broader and shifts to lower values of $2 \theta$. The maximum in the peak appears artificially sharp because adsorption of methane- $d_{4}$ markedly decreases the intensity of the 004 reflection of $\mathrm{C}_{8} \mathrm{~K}$ at $2 \theta=26^{\circ}$.

It has been observed in other neutron diffraction experiments on adsorbed species that adsorption may cause changes in the intensity of substrate reflection through cross interference terms [3]. There are a number of changes of the 001 reflection of the different substrates used here which may be combined qualitatively to determine the possible distance of methane from the surface. The most important changes are the large increase in the 002 reflection of graphon at $2 \theta=41^{\circ}$, the large decrease in the 004 reflection of $\mathrm{C}_{8} \mathrm{~K}$ at $26^{\circ}$ and the negligible change in the strong 002 reflection of $\mathrm{C}_{24} \mathrm{~K}$ at $2 \theta=33^{\circ}$. It may be shown by a simple treatment of diffraction in one dimension that the direction of the change is determined by the structure factor of the adsorbate molecule calculated as though it were in the lattice of the substrate (see also [3]). Calculations were made for methane as though it were freely rotating about all axes. There is little difference between the results from this model and one where the methane is fixed with three deuteriums pointing towards the surface. The 001 reflection of $\mathrm{C}_{24} \mathrm{~K}$ and the 004 and 008 reflection of $\mathrm{C}_{8} \mathrm{~K}$ are decreased in intensity and the 002 reflection of graphon enhanced when the carbon atom of methane is between 3.2 and $3.7 \AA$ from the surface. This is consistent with a value of $3.6 \AA$ calculated from Lennard-Jones parameters by Steele [15]. However, the very slight change in the 002 reflection of $\mathrm{C}_{8} \mathrm{~K}$ indicates that the methane carbon atom is close to $3.3 \AA$ from the surface. This is very much closer than the predicted value. It is hoped to do further experiments to refine this important calculation.

\subsection{THE STRUCTURE AND DYNAMICS OF AMMONIA} ON GRAPHON. - (a) Neutron Diffraction. - The adsorption of ammonia on graphon is quite different from that of methane. It follows a type III isotherm [16] indicating that ammonia tends to form multilayers rather than a monolayer on the surface. Below about $180 \mathrm{~K}$ (bulk melting point $=195 \mathrm{~K}$ ) the amount adsorbed actually decreases as the temperature is lowered. Values of isosteric enthalpies of adsorption in this temperature range indicate that the process of adsorption is closely related to that of melting.

When ammonia- $d_{3}$ is added to graphon and cooled to low temperatures new peaks appear whose positions and intensities are the same as those of bulk ammonia-d $\mathrm{d}_{3}$ [17]. The (111) and (200) peaks are clear of substrate reflections and may be observed down to statistical coverages as low as 0.5 though they disappear at about $0.25(80 \mathrm{~K})$. These results taken together with extensive isotherm measurements made recently by Bomchil at the Institut Laue-Langevin show that ammonia desorbs at low temperatures to form bulk solid.

As the temperature is increased the intensity of the ammonia peaks decreases slowly at first, and then quite sharply at temperatures well below the

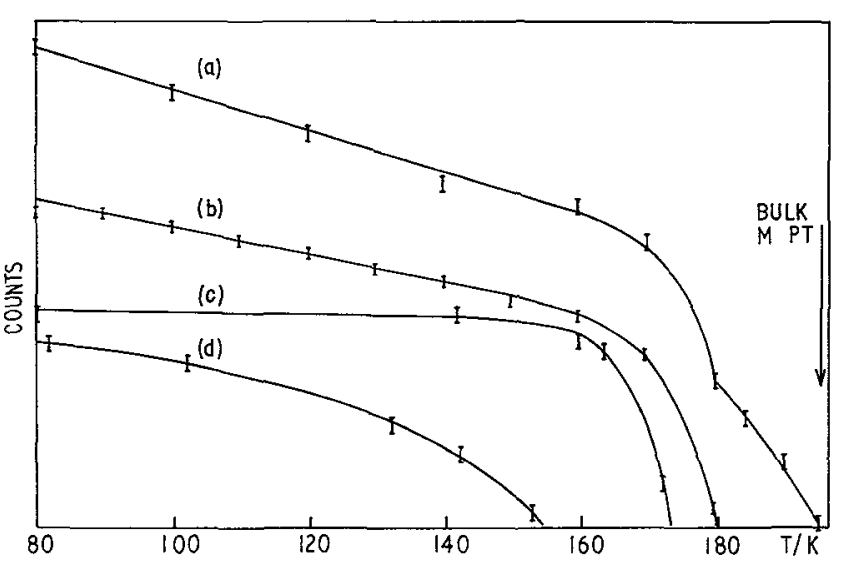

FIG. 3. - Intensity of (111) Diffraction Peak of $\mathrm{ND}_{3}$ as a function of Coverage and Temperature. (a) Coverage $(\theta)=6.0$. (b) $\theta=2.4$. (c) $\theta=1.0$. (d) $\theta=0.5$. The intensity scale is arbitrary (see text). . 
bulk melting point. The temperature at which the peaks completely disappear varies with coverage, appearing to approach a limiting value of about $180 \mathrm{~K}$ but, at high coverage, persisting up to the bulk melting point. This behaviour is shown in figure 3 . The relative intensity between the different curves in the figure is arbitrary being chosen to give the clearest representation of the behaviour at different coverage. Because the intensity of a peak is proportional to the amount of solid ammonia present, the curves in figure 3 are really melting curves of solid ammonia in contact with graphon. They show no hysteresis on cooling and heating and are therefore equilibrium curves.

Under normal conditions none of the ammonia- $d_{3}$ diffraction peaks is broader than the instrumental resolution function, but at low coverage and at temperatures where most of the ammonia has melted, the peaks are broadened slightly. Under these conditions a lower limit of $4000 \AA$ can be estimated for the particle size using the Scherrer formula [18].

All current theories of abnormally low melting points predict negligible differences from the bulk until the particle size is less than about $1000 \AA$ [19]. The melting phenomena observed here cannot therefore be associated with the presence of very small particles. The adsorption isotherms show that the capacity of the surface for ammonia increases steadily with increasing temperatures and then rapidly at about $180 \mathrm{~K}$. The melting curves measured by neutron diffraction are observing the equilibrium between bulk solid and adsorbed ammonia. Since the equilibrium pressure of ammonia over this temperature range is close to zero the melting curves are effectively adsorption isobars. There are some discrepancies between the neutron and isotherm measurements at low coverage. It seems probable that at low temperatures some of the ammonia is frozen into highly distorted crystallites or amorphous regions which would account for the discrepancies. There is some evidence from a closer examination of the diffraction patterns that some of the ammonia is distorted from its normal cubic structure.

An experiment which illustrates the delicate balance in the equilibrium between bulk solid ammonia and adsorbed ammonia is the effect on the melting curve of the addition of a monolayer of methane. The methane was added at a temperature above the melting point of ammonia. The result is shown in figure 4 . The presence of methane lowers the capacity of graphon to adsorb ammonia. Much of the ammonia is therefore forced off the surface to become bulk solid. The melting point is correspondingly increased.

There is little evidence from the diffraction patterns to indicate the structure of the adsorbed ammonia. At high coverage (4.0) when most of the

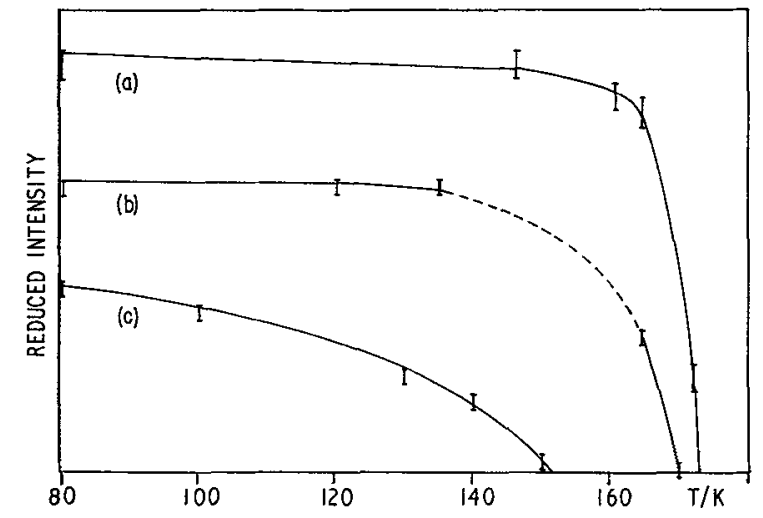

FIG. 4. - Melting Curves of $\mathrm{ND}_{3}$ on Graphon in the Presence of a Layer of Methane. (a) Coverage of $\mathrm{ND}_{3}=1.0$. (b) Coverage of $\mathrm{ND}_{3}=0.5, \mathrm{CH}_{4}=1.0$. (c) Coverage of $\mathrm{ND}_{3}=0.5$.

ammonia has melted, there is a broad peak with a maximum close to that of the graphite 002 peak, and a long tail extending to higher angles. This is characteristic of a liquid phase but it is not easy to decide just how two or three-dimensional is the structure of the liquid.

(b) Neutron Quasielastic Scattering. - The basis of incoherent neutron quasielastic scattering is that a monochromatic beam of neutrons is Doppler broadened by collision with protons undergoing different kinds of motion in the sample. Analysis of the shape and width of the broadening gives the frequency spectrum of individual proton motions averaged over the whole sample, which may then be related to molecular diffusion. Because the neutron wavelength is comparable with typical distances of molecular motion the variation of the Doppler broadening with momentum transfer depends on the spatial characteristics of the molecular motion in the sample. For example, translational and rotational diffusion are readily distinguished in this way [20].

Quasielastic spectra of ammonia on graphon were measured at three different coverages at $205 \mathrm{~K}$, and at a coverage of 1.0 over the temperature range $130 \mathrm{~K}$ to $245 \mathrm{~K}$ (bulk melting point $=195 \mathrm{~K}$, boiling point $=240 \mathrm{~K}$ ). The experiments were made on the multichopper time of flight spectrometer, IN5, at the Institut Laue-Langevin with a resolution of $50 \mu \mathrm{eV}$ and an incident wavelength of $8 \AA$. The long wavelength used is above the Bragg cut-off for graphite which effectively increases the transparency of the substrate to neutrons.

In figure 5 are shown spectra of a monolayer of ammonia on graphon at temperatures of 130,163 and $185 \mathrm{~K}$ with the graphon background subtracted. The spectra shown have been corrected from the raw time of flight data and are closely related to a convolution of the scattering law, $S(Q, \omega)$ with the machine resolution function. They are shown for two scattering angles corresponding to momentum transfers of 1.1 and $0.9 \AA^{-1}$. 


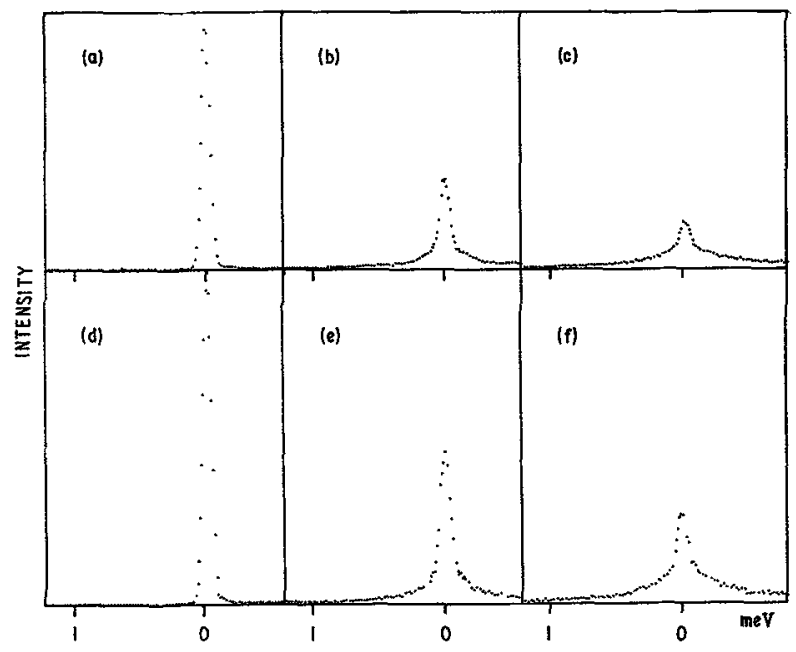

FIG. 5. - Quasielastic Scattering Spectra of $\mathrm{NH}_{3}$ on Graphon. Coverage $=1.0$. Background has been subtracted. (a) $T=130 \mathrm{~K}$ $Q=1.1 \AA^{-1} \quad$ (b) $T=163 \mathrm{~K}, Q=1.1 \AA^{-1} \quad$ (c) $T=185 \mathrm{~K}$, $Q=1.1 \AA^{-1} \quad$ (d) $T=130 \mathrm{~K}, Q=0.9$ (e) $T=163 \mathrm{~K}, Q=0.9$ (f) $T=185 \mathrm{~K}, Q=0.9$.

The spectra at $130 \mathrm{~K}$ show no broadening of the incident beam. At this temperature all the ammonia is therefore immobile on a time-scale shorter than about $10^{-10}$ second. As the temperature increases the intensity of the central peak decreases and a broad component starts to appear. Above $185 \mathrm{~K}$ the relative intensities of the two components remain the same up to $245 \mathrm{~K}$ although the broad component becomes much wider. These results show that there is an equilibrium between a form of solid ammonia and a rapidly diffusing form. By comparison of the relative intensities of the peaks with the melting curves obtained by neutron diffraction (Fig. 3) and the isotherm data, it is clear that the immobile ammonia may be identified with bulk solid crystallites, while the mobile species is ammonia actually adsorbed on the graphon surface. Even at temperatures where the ammonia has supposedly all melted, an unbroadened central peak remains, corresponding to $10-20 \%$ of the ammonia present. Ammonia is known to exhibit a peculiar type of hysteresis on graphitized carbon blacks [21] which has been attributed to intercalation of a small fraction into the graphite layers. We found no evidence of expansion of the layers from diffraction patterns. It is possible, however, that some ammonia lodges in faults in the highly defective graphon structure. This could then give rise both to hysteresis of the kind observed and an unbroadened component of the quasielastic peak.

The range of momentum transfer, $Q$, over which a quantitative analysis of the broad component may be made is restricted by the extensive small angle scattering which makes accurate subtraction of the background impossible below a $Q$ of about $0.5 \AA^{-1}$. Within the range $Q=0.5-1.2 \AA^{-1}$ analysis of the broadening shows that it depends on $Q^{2}$ at $245 \mathrm{~K}$ but
TABLE II

Translational Diffusion Coefficients $\left(\times 10^{5} \mathrm{~cm}^{2} \mathrm{~s}^{-1}\right.$ ) for Ammonia Adsorbed on Graphon

Values given for bulk ammonia are calculated from reference [22].

$\begin{array}{cccccc}\begin{array}{c}T / \mathrm{K} \\ \text { Coverage }\end{array} & 130 & 163 & 185 & 205 & 245 \\ - & - & - & - & - & - \\ 0.5 & - & - & - & 7.9 & - \\ 1.0 & 0 & 3.5 & 4.9 & 6.5 & 9.7 \\ 2.0 & - & - & - & 5.5 & - \\ \text { Bulk } & & (0.8) & (1.6) & 2.8 & (6.4)\end{array}$

The bulk melting and boiling points are $195 \mathrm{~K}$ and $240 \mathrm{~K}$ respectively.

as the temperature is lowered this decreases to a $Q$ dependence at 163 and $185 \mathrm{~K}$. This indicates that the motion is more complicated than simple translational diffusion. Neglecting this for the moment, values of translational diffusion coefficients may be calculated at a single value of $Q\left(1.1 \AA^{-1}\right.$, chosen because the statistics were very much better at that angle). The results are shown in table II together with values for the bulk liquid [22]. The rate of diffusion is much greater for adsorbed ammonia than for ammonia in the bulk liquid and the activation energy is reduced by half. Ammonia is an anomalous liquid in the sense that comparison with molecules of similar molecular weight suggests that it would remain a gas down to temperatures below $163 \mathrm{~K}$ if it were not for the formation of an extensive hydrogen bonded network. This network is broken down by the surface and the rate of diffusion is correspondingly much larger than in the liquid. Consistent with this explanation is the decrease in the diffusion coefficient as the coverage is increased (at $205 \mathrm{~K}$ ).

For simple translational diffusion in a liquid obeying Fick's law the quasielastic scattering should have a Lorentzian shape and the broadening should vary with $Q^{2}$. This is observed for adsorbed ammonia at $245 \mathrm{~K}$. At lower temperatures the broadening changes over to a $Q$ dependence. Firstly, for two dimensional diffusion averaged over all directions the scattering law is no longer a Lorentzian [23]. The shape of the peak becomes sharper nearer its centre. After convolution with the machine resolution function the broadening varies much less strongly with $Q$. Both these effects are observed in the present spectra especially at low temperatures and coverage. It seems likely that the reduced $Q$ dependence of the broadening is associated with more marked two dimensional motion under these conditions. The three dimensional character of the diffusion at $245 \mathrm{~K}$ shows that ammonia increasingly tends to form multilayers at higher temperatures. Two other possible explanations of the $Q$ dependence are that 
the motion is a combination of translational diffusion with either rotational diffusion or a limiting jump rate determined by the periodic potential of the substrate. Either could account qualitatively for the observed behaviour [20] though neither would be easy to establish quantitatively.

\section{References}

[1] KJems, J. K., Passell, L., Taub, H., Dash, J. G., Novaco, A. D., Phys. Rev. B 13 (1976) 1446.

[2] Bourdon, A., Marti, C., Thorel, P., Phys. Rev. Lett. 35 (1975) 544.

[3] Thorel, P., Croset, B., Marti, C., Coulomb, J.-P. Proceedings of Gatlinburg Conference on Neutron Scattering (1976).

[4] Verdan, G., Helv. Phys. Acta 41 (1968) 533.

[5] Todireanu, S., Hautecler, S., Phys , Lett. 43A (1973) 189.

[6] Coulomb, J.-P., Kahn, R., Bienfait, M., Surf. Sci. 61 (1976) 291.

[7] DASH, J. G., Films on Solid Surfaces (Academic Press, New York) 1975.

[8] Ash, S. G., FindenegG, G. H., Spec. Discuss. Faraday Soc. on Thin Liquid Films and Boundary Layers (1971).

[9] Everett, D. H., Parfitt, G. D., Sing, K. S. W., Wilson, R., J. Appl. Chem. Biotechnol. 24 (1974) 199.

[10] SaeHr, D., Herold, A., Comptes Rendus 250 (1960) 545.

[11] Ross, S., Ol.Iver, J. P., On Physical Adsorption (Interscience, New York), 1964.

[12] Thому, A., Duval, X., J. Phys. Chim. 67 (1970) 1101.
[13] Тному, A., Duval, X., J. Phys. Chim. 66 (1969) 1966.

[14] Warren, B. E., Phys. Rev. 59 (1941) 59.

[15] Steele, W. A., The Interaction of Gases with Solid Surfaces (Pergamon, Oxford), 1974.

[16] Beebe, R. A., Kiselev, A. V., Kovalera, N. V., Tyson, R. F. S., Holmes, J. M., Russ. J. Phys. Chem. 38 (1964) 372 .

[17] ReEd, J. W., Harris, P. M., J. Chem. Phys. 35 (1961) 1730.

[18] GuINIER, A., X-ray Diffraction (Freeman, San Francisco), 1963.

[19] Peppiatt, S. J., Sambles, J. R., Proc. Roy. Soc. (London) A 345 (1975) $387,401$.

[20] Springer, T., Quasielastic Neutron Scattering for the Investigation of Diffusive Motions in Solids and Liquids (Springer, Berlin), 1972.

[21] Holmes, J. M., Beere, R. A., J. Phys. Chem. 61 (1957) 1684.

[22] Goyal, P. S., Dassanacharya, B. A., Thaper, C. L. Tyengar, P. K., Proc. Nucl. Phys. \& Sol. State Phys. Symp. 3 (1970) 457.

[23] Rosciszewski, K., Acta Phys. Pol. A 41 (1972) 549.

\section{DISCUSSION}

J. FRIPIAT. - Don't you find it surprising that there is no rotational contribution in such a hydrogen bonded liquid as ammonia?

R. K. THOMAS. - These may be a rotational contribution to the diffusion of the protons. If it takes place at a similar rate to translational diffusion, the two motions could not be separated. Presumably in such an open fluid as adsorbed ammonia rotational diffusion is rapid.

M. BIENFAIT. - Could you summarize the latest adsorption measurements of ammonia/graphon made by Bomchil ?

R. K. Thomas. - These measurements are presently to be submitted for publication. Isotherms in the temperature range $150-210 \mathrm{~K}$ have been measured. In the top temperature range, they agree with that determined by Beebe. Though there are slight differences from these determined by Kiselev for ammonia on Sterling MT (3100). This may be attributed to the lower homogeneity of Vulcan III.

F. A. PUTNAM. - Your figure showed that the distance between graphite and methane was a function of density. Could you comment on this ?

R. K. Thomas. - The distance increases by $1 \%$ when the coverage increases from 0.7 to 1 monolayer. For our present results this is close to the experimental error and should not be taken too seriously.

W. STEELE. - In calculations of the diffraction due to cross-correlations between ad-molecules and substrates, what is the effect of including ad-molecules on both exposed faces of these very thin crystals ?

R. K. THOMAS. - The effect of adsorption on the second face on the intensity enhancement will be exactly the same as on the first.

J. P. McTague. - Have you considered the influence of molecular form factor on the fitting of the $(00 l)$ interference peaks? It would seem that, especially for the graphite (004) peak, the value of the distance parameter might be somewhat sensitive to assumption about whether the molecules sit rigidly or librate.

R. K. Thomas. - Only in a crude way by replacing the discrete deuterium atoms by a continuous spherical distribution. We shall shortly examine the rotational motion of methane on the surface using neutron quasi-elastic scattering. We should then be able to include in the model an accurate molecular form factor. In any case, $Q$ only changes slightly across the peak so that even a poor approximation for the form factor should have little effect on the accuracy of the calculation.

Y. LARHER. - I have measured an adsorption isotherm of $\mathrm{NH}_{3}$ on natural graphite. It shows a step at a relative pressure of about 0.6 , clearly indicating the formation of a monolayer. Similar results have been published many years ago for the adsorption of $\mathrm{NH}_{3}$ on graphitized carbon black.

R. K. Thomas. - I would be glad to see these results. 